\title{
Büro Binaları Acil Tahliye Senaryolarının Simülasyon Destekli Oluşturulması
}

\author{
*,1 Recai Aksoy, ${ }^{2}$ Gökhan Coşkun, ${ }^{3,4}$ Hakan Serhad Soyhan \\ *1 Sakarya Üniversitesi, Fen Bilimleri Enstitüsü, Yangın Güvenliği ve Yanma EABD, \\ 54150, Serdivan - Sakarya, recaiaksoy@ gmail.com, \\ ${ }^{2}$ Sakarya Üniversitesi, Mühendislik Fakültesi, Makine Mühendisliği Bölümü ve Fen Bilimleri Enstitüsü, Yangın Güvenliği ve \\ Yanma EABD, 54150, Serdivan -Sakarya, gcoskun@sakarya.edu.tr, \\ ${ }^{3}$ Sakarya Üniversitesi, Mühendislik Fakültesi, Makine Mühendisliği Bölümü ve Fen Bilimleri Enstitüsü, Yangın Güvenliği ve \\ Yanma EABD, hsoyhan@sakarya.edu.tr, 54150, Serdivan-Sakarya, \\ 4 Team-San Ltd.Şti., Sakarya Üniversitesi, Teknokent, hsoyhan@teamsan.com.tr, 54150, Serdivan -Sakarya

$\ddot{O} z$

Son yıllarda, hızlı nüfus artışı ve ekonomik gelişmeler sonucunda ülkemizde büro binalarının sayısında önemli artışlar görülmektedir. İnşa edilen bu binalar oldukça büyük ve mimari açıdan karmaşık tasarıma sahip olmaktadırlar. Bu tip karmaşık yapılara sahip büro binalarının inşasından sonra hatalı projelendirmenin değiştirilebilmesinin zorluğundan ve yüksek maliyetlerinden dolayı yangın tesisatı ve acil durumlarda binada bulunanların tahliye senaryoları, bina proje aşamasında iken planlanmalıdır. Büro binaları da bu planları dikkate alarak özenle inşa edilmelidir. Ayrıca bina içerisinde çalışanların sayısı ve yerleşimine göre belirli aralıklarla tahliye senaryoları geliştirimleri ve tatbikatlar uygulanmalıdır. Tahliyenin önceden planlanmış senaryolara bağlı olarak başlamaması halinde, optik yoğunluk sonucu boğulma kaynaklı ölümlerle karşılaşma oranı azımsanmayacak kadar fazladır. Bu sebeple mutlaka güncel tahliye senaryoları hazırlanmalı, mümkün olduğu kadar tatbikatlar yapılmalı ve gelişen yazılım teknolojisini kullanılarak en efektif tahliye senaryosunun tespiti yapılmalıdır. Bu çalışmada, hem insani hem de yapısal tahliye unsurları ile ilgili olarak 6 farklı senaryo hazırlanmış ve bu senaryoların tatbikatı bilgisayar destekli simülasyonlar yardımıyla yapılmıştır. Elde edilen sonuçlar neticesinde en uygun tahliye senaryosu tespit edilmiştir.

Anahtar Kelimeler: Yangın, Tahliye, Simülasyon, Tahliye Planları, Senaryo

\section{Simulation for Office Buildings Emergency Evacuation Scenarios}

\author{
*,1 Recai Aksoy, ${ }^{2}$ Gökhan Coşkun, ${ }^{3,4}$ Hakan Serhad Soyhan \\ *,1 Sakarya Üniversitesi, Fen Bilimleri Enstitüsü, Yangın Güvenliği ve Yanma EABD, \\ recaiaksoy@gmail.com, 54150, Serdivan -Sakarya
}

${ }^{2}$ Sakarya Üniversitesi, Mühendislik Fakültesi, Makine Mühendisliği Bölümü ve Fen Bilimleri Enstitüsü, Yangın Güvenliği ve Yanma EABD, 54150, Serdivan -Sakarya, gcoskun@sakarya.edu.tr, ORCID: 0000-0003-1485-4325

${ }^{3}$ Sakarya Üniversitesi, Mühendislik Fakültesi, Makine Mühendisliği Bölümü ve Fen Bilimleri Enstitüsü, Yangın Güvenliği ve Yanma EABD, hsoyhan@sakarya.edu.tr, 54150, Serdivan -Sakarya

${ }^{4}$ Team-San Ltd.Şti., Sakarya Üniversitesi, Teknokent, hsoyhan@teamsan.com.tr, 54150, Serdivan -Sakarya

\begin{abstract}
In recent years, because of population growth and economic developments, there has been a significant increase in the number of Office Buildings in our country. Due to the difficulties and high costs of changing the faulty project of these kind of complex buildings, the emergency case evacuation scenarios should plan while the building is in project phase. Office buildings should
\end{abstract}

*Sorumlu Yazar: Recai Aksoy, Sakarya Üniversitesi, Fen Bilimleri Enstitüsü, Yangın Güvenliği ve Yanma EABD, recaiaksoy@gmail.com , +90 5052043197

Bu çalışma ISHAD2018'de sunulan bildiriden türetilmiştir. 
also be carefully constructed considering these plans. In addition, evacuation scenarios should be develop and apply depending on locations and number of the occupant in the building. If the extraction does not start due to a pre-planned scenario, optical density may be associated with death from asphyxiation. For this reason, current evacuation scenarios should be prepared, fire drills should be made as much as possible and the most effective evacuation scenario should be determined by using developing software technology. In this study, six different scenarios were prepared for human and structural evacuation elements and simulated using an evacuation software. From the simulation results, the most appropriate evacuation scenario was determined.

Keywords: Fire, Evacuation, Simulation, Evacuation Plans, Scenarios

\section{GIRIŞ}

Günümüz büro binalarında farklı yaş gruplarında insanlar bulunmakta ve acil durumlarda hızlı bir şekilde yapılması gereken tahliye kişilerin hareket yeteneği, tahliye eğitimi alıp almamaları ve tahliye yönergelerinin yetersiz olması nedeniyle büyük oranda etkilenmektedir. Binadaki insanların tahliyesinde, acil kaçış noktaları etkin bir şekilde belirlenmeli ve tahliye için farklı senaryolar planlanarak en uygun senaryo seçilip aksiyon planına eklenmelidir.

Geçerli yönetmelik ve standartların belirlediği gereklilikler ve kurallara uyulması durumunda bile ortaya çıkacak sonuçlar tam olarak bilinememektedir [1]. Yönetmeliklerdeki maddelerin ve kuralların birebir uygulandığı birçok değişik biçimde hallerde bile, bina boşaltım süresi veya acil çıkış genel durumlarını etkileyen değişkenler doğru olarak değerlendirilememektedir.

Bu sebeple, yönetmelikteki maddelerin birebir uygulanması ile yapılan bir tasarım aşamasında dahi, özellikle binayı işgal eden kullanıcıların tipinin antropometrik özelliklerden kaynaklanan farkl1lıklar nedeniyle beklenen tahliye sürelerinde ciddi tutarsızlıklar oluşmaktadır.

$\mathrm{Bu}$ durumda bina yapısı, mobilya yerleşimi, binayı kullanan kişilerin antropometrik özelliklerinin ve hatta yangın dumanının tahliye olan kişiler üzerindeki etkilerinin de modellenebildiği bilgisayar yazılımları sayesinde çok daha detaylı ve doğru tahliye süresi hesabı yapılabilmektedir. $\mathrm{Bu}$ sayede acil tahliye koşullarını farklı senaryolar ile tatbikat yapmadan incelemek mümkün olmakta ve böylece tahliye simülasyonların yapılması önem kazanmaktadır.

$\mathrm{Bu}$ simülasyonların yapılmasındaki diğer önemli husus da büro binalarının sabit çalışanlar dışında dışarıdan gelen farklı özellikteki kullanıcıları da barındırmasıdır. Bu sebeple tahliyede risk faktörü artmakta ve olumsuz birçok etkisi görülmektedir [2].

Tüm bu risk etmenleri göz önünde bulundurulduğunda, farklı acil tahliye senaryolarının meydana getirilmesi hem acil tahliye yönünden hem de yaşam güvenliği önlemleri bakımından büyük önem arz etmektedir.

$\mathrm{Bu}$ çalışmada binalar için hazırlanan acil durum yönetmelikleri yangından korunma ve tahliye açısından incelenmiştir. Ayrıca örnek bir büro binası için 6 farklı senaryo kullanılarak tahliye süreleri tespit edilmiştir ve elde edilen bulgular değerlendirilmiştir.

\section{Binaların Yangından Korunması Hakkındaki Yönetmelikler}

2015 tarihli binaların yangından korunması hakkındaki yönetmelik (BKHY-2015) hızlı tahliye için uyulması gereken kuralları ve tahliyenin başlaması için kritik öneme sahip yangın uyarı sistemlerini kullanım koşullarını içermektedir. Detaylandırılmış bir yönetmelik olmasına karşın dinamik yapıya sahip büro binaları için, bina özeline inilerek daha detaylı planların yapılması gerektiği anlaşılmaktadır.

\subsection{Madde 159 (1)}

Binaların yangından korunması hakkında yönetmeliğin 159. maddesine göre büro binalarında en az 2 bağımsız kaçış merdiveni veya başka çıkışların sağlanması gerekir.

Ancak;

a) Yap1 yüksekliğinin 21.50 m’den az olması,

b) Bir kattaki kullanıcı sayısının 50 kişiden az olması,

c) Bütün katlarda en fazla kaçış uzaklığının Ek-14'teki uzaklıklara uygun olması,

ç) Yapımda yanmaz ürünler kullanılmış olması,

d) İmalat ve depolamada kolay alevlenici ve parlayıcı maddeler kullanılmaması, şartlarının hepsinin birlikte gerçekleşmesi hâlinde tek kaçış merdiveni yeterlidir [3].

\subsection{Madde 161 (1), Madde-75, Ek-7}

$5000 \mathrm{~m}^{2}$ 'yi geçen tüm büro binalarında algılama ve uyarı sistemi uygulanır [3].

Yönetmelik maddelerinde belirtilen tasarım kıstasları ile büro binalarındaki kullanıcıların acil durum anında hızlıca ve karmaşaya mahal vermeyecek şekilde akış oluştuğunu varsaymak, bu değerlerle acil çıkış yolu uzunluklarını ve bina boşaltım zamanlarını tespit etmek, yangın ve yaşam güvenliğini sağlayabilmek adına yeterli ve güvenilir neticeler vermemektedir.

Binaların Yangından Korunması Hakkındaki Yönetmelik2015 ile tayin edilen düşük yangın tehlikesine sahip mekanların kullanım alanları Tablo-1'de açıklanmıştır. 
Tablo 1. Düşük tehlike kullanım alanları [3]

\section{EK-1/A Düșük Tehlike Kullanım Alanları}

Düşük yangın yüküne sahip,düşük yanabilirliği olan ve yangına karşı direnci en az 30 dakika olan 126 m2'den büyük bölümü olmayan mekânlar.Okullar ve diğer eğitim kurumları (belirli alanları*), bürolar (belirli alanları*), hapishaneler

* Kullanım alanları, Ek-1.b ve Ek-1.c kapsamına girmeyen alanlar.

Tablo 2'de görüldüğü gibi (BKHY-2015) ile belirlenen yangına dayanım (direnç) süreleri, binanın kullanım sınıflarına göre ayrılmaktadır.

Tablo 2. Bina kullanım sınıflarına göre yangına dayanım süreleri [3]

\begin{tabular}{|c|c|c|c|c|c|c|}
\hline \multicolumn{7}{|c|}{$\begin{array}{c}\text { Ek-3/C Bina Kullanım Sınıflarına Göre Yangına } \\
\text { Dayanım (Direnç) Süreleri }\end{array}$} \\
\hline \multirow{4}{*}{ 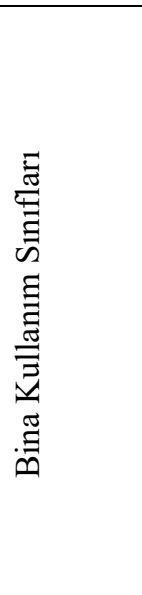 } & \multicolumn{6}{|c|}{$\begin{array}{l}\text { Yapı Elemanlarının Yangına Dayanım } \\
\text { Süreleri (dk.) }\end{array}$} \\
\hline & \multirow{2}{*}{\multicolumn{2}{|c|}{$\begin{array}{l}\text { Bodrum } \\
\text { Katlar } \\
\text { (üstündeki } \\
\text { döşeme } \\
\text { dahil) } \\
\text { Bodrum } \\
\text { Katların } \\
\text { Derinliği } \\
(\mathrm{m}) \\
\end{array}$}} & \multicolumn{4}{|c|}{ Giriş veya Üst Katlar } \\
\hline & & & \multicolumn{4}{|c|}{ Bina Yüksekliği (m) } \\
\hline & 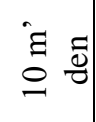 & 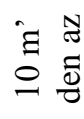 & 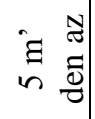 & 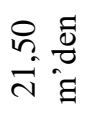 & 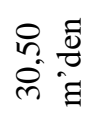 & 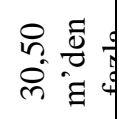 \\
\hline \multicolumn{7}{|c|}{ 4. Büro Binaları } \\
\hline $\begin{array}{l}\text { *yağmurl } \\
\text { ama } \\
\text { sistemi } \\
\text { yok }\end{array}$ & 90 & 60 & 30 & 60 & 90 & $\begin{array}{c}\text { İzin } \\
\text { veril } \\
\text { mez }\end{array}$ \\
\hline $\begin{array}{l}\text { *yağmurl } \\
\text { ama } \\
\text { sistemli }\end{array}$ & 60 & 60 & 30 & 30 & 60 & 120 \\
\hline
\end{tabular}

BYKHY-2015 Ek5/A'da tanımlanan Büro Binalarında, konferans salonu, mutfaklar, resepsiyon alanları, bekleme alanları, atrium zemini için alınması gereken kullanıcı yükü katsayıları tablo 3'de verilmiștir.
Tablo 3.Kullanıcı yükü katsayıları [3]

\begin{tabular}{|c|c|c|c|}
\hline \multicolumn{4}{|c|}{ Ek-5/A Kullanıcı Yükü Katsayısı Tablosu } \\
\hline & \multicolumn{2}{|l|}{ Kullanım Alanı } & M2/kişi \\
\hline 1 & \multicolumn{2}{|c|}{$\begin{array}{l}\text { Konferans salonu, çok amaçlı salonlar } \\
\text { (balo vs), lokanta, kantin, bekleme } \\
\text { salonları, konser salonları, sinema ve } \\
\text { tiyatro salonları, topluma açık stüdyo, } \\
\text { düğün salonu vb. }\end{array}$} & 1.5 \\
\hline \multirow[t]{2}{*}{2} & \multirow{2}{*}{$\begin{array}{l}\text { Dans salonları, } \\
\text { bar, gece } \\
\text { kulüpleri ve } \\
\text { benzeri yerler }\end{array}$} & $\begin{array}{l}\text { Oturulan kısımları } \\
\text { için }\end{array}$ & 1.0 \\
\hline & & $\begin{array}{l}\text { Ayakta durulan } \\
\text { k1sımları için }\end{array}$ & 0.5 \\
\hline 3 & \multicolumn{2}{|c|}{$\begin{array}{l}\text { Sergi alanları, stüdyolar (film, radyo, } \\
\text { televizyon, kayıt) }\end{array}$} & 1.5 \\
\hline 4 & \multicolumn{2}{|c|}{$\begin{array}{l}\text { Terminallerin yolcu gelip gidip } \\
\text { bekleme salonları }\end{array}$} & 3 \\
\hline 5 & \multicolumn{2}{|c|}{$\begin{array}{l}\text { Derslikler, bilgisayar odaları, seminer } \\
\text { salonları }\end{array}$} & 1.5 \\
\hline 6 & \multicolumn{2}{|c|}{$\begin{array}{l}\text { Resepsiyon alanları, bekleme alanları, } \\
\text { atrium zemini }\end{array}$} & 3 \\
\hline
\end{tabular}

BYKHY-2015 Ek5/B'de tanımlanan Büro Binaları için tek yönde ve çift yönde tahliye noktalarına götüren en uzun tahliye noktası mesafeleri tablo 4'de görülmektedir

Tablo 4.Çıkışlara götüren en uzun kaçış uzaklıkları [3]

\begin{tabular}{|c|c|c|c|c|c|c|c|c|c|c|}
\hline \multicolumn{11}{|c|}{ Ek-5/B Çıkışlara Götüren En Uzun Kaçış Uzaklıkları } \\
\hline \multirow[t]{3}{*}{$\begin{array}{l}\Xi \\
\Xi \\
\bar{\Xi} \\
\overline{0} \\
\Xi \\
\bar{\Xi} \\
\bar{\Xi}\end{array}$} & \multicolumn{2}{|c|}{ 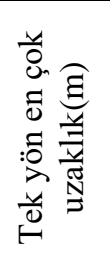 } & \multicolumn{2}{|c|}{ 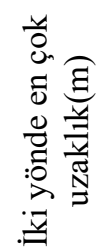 } & \multicolumn{4}{|c|}{$\begin{array}{l}\text { Birim genişlik } \\
\text { için kişi sayısı }\end{array}$} & \multicolumn{2}{|c|}{$\begin{array}{c}\text { Çıkmaz } \\
\text { koridor } \\
\text { en çok } \\
\text { uzaklık }(\mathrm{m})\end{array}$} \\
\hline & \multirow{2}{*}{\multicolumn{2}{|c|}{ 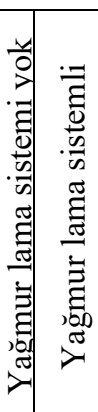 }} & \multirow{2}{*}{ 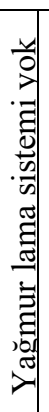 } & \multirow{2}{*}{ 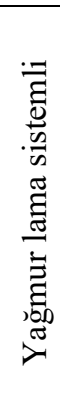 } & \multicolumn{2}{|c|}{$\begin{array}{c}\text { Kap1 } \\
\text { Açıklıkla } \\
\text { rında }\end{array}$} & \multirow{2}{*}{ 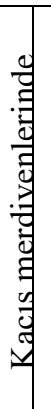 } & \multirow{2}{*}{ 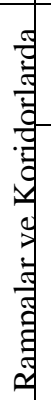 } & \multicolumn{2}{|c|}{ Koridorlar } \\
\hline & & & & & 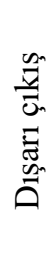 & 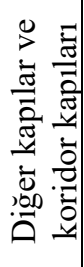 & & & 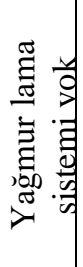 & 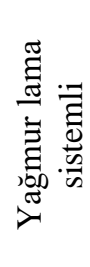 \\
\hline 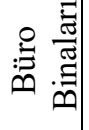 & $n$ & ల & 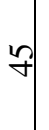 & $n$ & 8 & 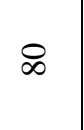 & & 국 & 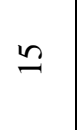 & ๙ి \\
\hline
\end{tabular}


Tablo 5'de verildiği gibi BYKHY-2015 Ek5/B'de tanımlanan Büro Binaları için binalarda özellikle orta ve büyük kapasiteli endüstriyel tesisler ile kullanım alanı 5,000 $\mathrm{m}^{2}$ 'den fazla tüm Büro Tarzı Binalarda yangın algılama sistemi yapılması mecburidir.

Tablo 5. Otomatik algilama sistemi gereken binalar [3]

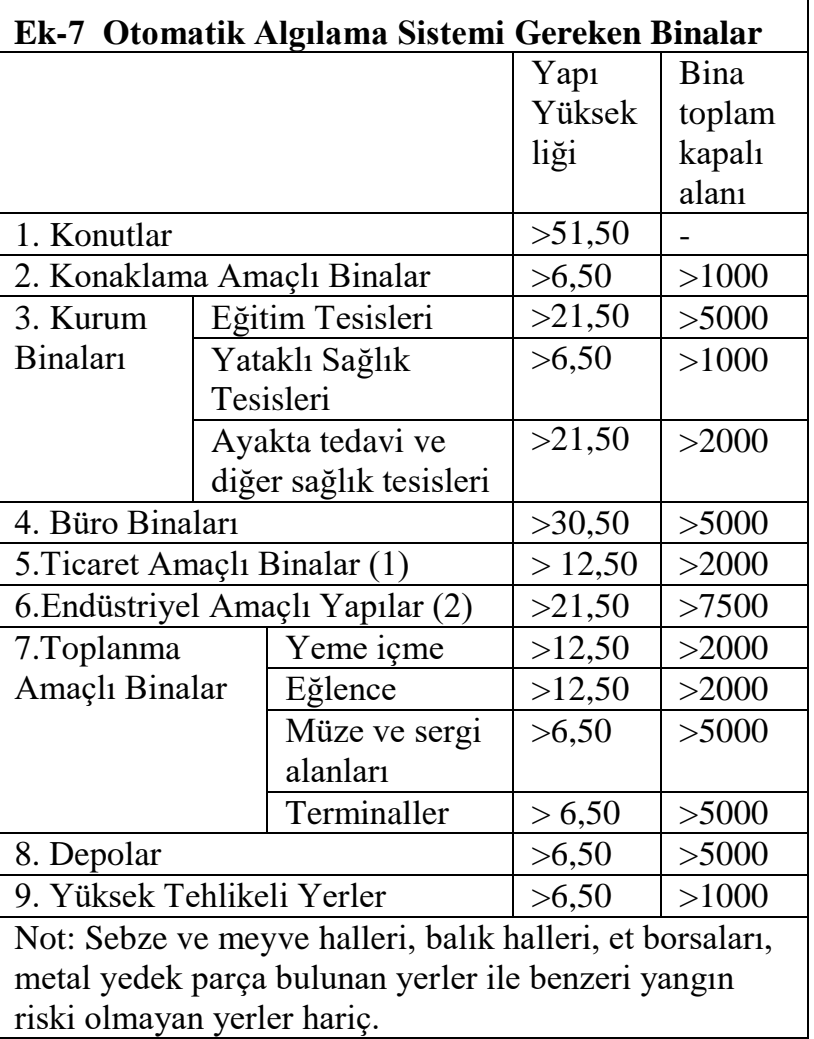

$\mathrm{Bu}$ tanımlamalar ile yönetmeliğin ana hatları belirlenmiş olup, büro binalarının dizaynı için kâfi kabul görülmüştür. $\mathrm{Bu}$ donelerin yeterliliği olağan koşullarda sadece acil durum lahzasında deney edilebilmektedir [4]. Farklı bina kullanıcılarının hep beraber olduğu ve planlanan tasarımın sonuçlarının tecrübe edilmesinin gerçekleştirilebilmesi ve neticelerinin değerlendirilmesi için, tüm kullanıcıların süratleri, duruş açıklıkları, yaşları gibi pek çok genel husus dikkate alınarak can ve yangın emniyeti imkanlarını imtihan eden Acil Tahliye Simülasyonları ehemmiyet kazanmaktadır.

\section{DURUM ÇALIŞMASI}

Acil hallerde binada bulunan tüm insanların, binadan ayrıldıkları gerçek zamanı hesap etmek, can, meta ve yangın emniyeti için alınan tedbirlerin kiyafetliğini sınamak için kullanılan metot olan simülasyon, tüm dünyada birçok uygulaması bulunan ve gittikçe daha fazla kullanılmaya başlanan bir metottur. Yapının dizaynı süresince kullanılarak yapılan küçük değişiklikler ile ciddi sorunlara yol açabilecek durumları engelleyebilecek önlemlerin alınmasında önemli seviyede katkıda bulunabilmektedir. Acil Tahliye Simülasyonları, doğru donelerle gerçek zamanlı bir dizayn yapmaya imkan temin ettiği gibi, yangın tahliye tasarımlarında tolere edilebilen zaman unsuru, insanların toplumsal davranışları ve genel özellikleri tasarım değişkenlerine eklenebilmesini sağlayabilmektedir [5]. Binada bulunan insanların davranışları, binanın kullanım sınıfı tahliye planlarında doğrudan ilişkili olup, göz önünde bulundurulması gereken önemli bir husustur. Bir binanın yangın güvenliği yönetmeliği koşullarını sağlarken, binanın içinde bulunan insanları de binanın bir parçası olarak saymak, can, meta ve yangın emniyetini hesaba katarak tasarımı oluşturmak, acil durum anında karmaşayı azaltarak tahliye zamanını kısaltacaktır. Acil durumda insanlar toplu devinim halinde bulunurlar [6]. Toplu hareket neticesinde izdihamın en çok oluştuğu alanlar, tahliye simülasyonu ile belirlenerek, koridor genişlikleri ve kapı aralık mesafeleri arttırılmalıdır.

$\mathrm{Bu}$ çalışmada büro binasındaki acil tahliye durumu için toplamda 6 farklı senaryo düşünülerek Pathfinder [7] simülasyon programı ile tahliye simülasyonları yapılmıştır. Simülasyon süreleri boyunca tespit edilen, insan hareketleri, yı̆̆ılmaları ve toplan tahliye süreleri simülasyondan elde edilen görseller ve tablolar yardımıyla verilmiştir. Tablo 6'da senaryoların detayları görülmektedir. Tahliye simülasyonu senaryolarında farklı çıkış kapıları seçilmiştir. Bunun nedeni bina içerisinde yangının çıktığı bölgeye göre bazı kapılardan tahliyenin mümkün olamayabileceğinin göz önüne alınmasıdır. Bu sebeple tahliye senaryolarında farklı kapılardan olan tahliye sürelerinin tespit edilmesi önemli olduğu düşünülmüştür. Ayrıca kaosun yaşandığı tahliye durumları, planlı ve düzenli tahliye durumları hatta binada engelli bireylerin bulunduğu ve onlara özel olarak hazırlanan tahliye operasyonu da senaryolara eklenmiştir.

Tablo 6. Farklı tahliye senaryoları

\begin{tabular}{|c|c|}
\hline SENARYO & Açıklama \\
\hline 1 & $\begin{array}{l}\text { Kaotik ortamda sadece bina arka acil çıkıŞ } \\
\text { kapısının açık olduğu ve bu ortamda } \\
\text { insanlar sürü psikolojisi ile hareket } \\
\text { ettikleri durum. }\end{array}$ \\
\hline 2 & $\begin{array}{l}\text { Toplu, bilinçli ve düzenli tahliyenin } \\
\text { olduğu ve bina tahliye ekiplerinin görev } \\
\text { yaptığı durumda sadece bina ön normal } \\
\text { çıkış kapısının tahliyede kullanılması. }\end{array}$ \\
\hline 3 & $\begin{array}{l}\text { Acil durum ekiplerinin yetersiz kaldığ } 1 \\
\text { durumdaki kaos sonucu insanların en } \\
\text { yakındaki sağ ön acil çıkış kapısına } \\
\text { gittikleri senaryo. }\end{array}$ \\
\hline 4 & $\begin{array}{l}\text { Kaotik ortam sonucu oluşan yı ğılmalardan } \\
\text { dolayı ortamdaki insan optik yoğunluğu } \\
\text { arttığı ve insanların birbirini ezme riskinin } \\
\text { olduğu senaryo. }\end{array}$ \\
\hline 5 & $\begin{array}{l}\text { Günümüz dünyasında engelsiz hayatın } \\
\text { farkındalığını arttırmak adına simülasyon } \\
\text { çalışması yapılarak eksikliklerde göz } \\
\text { önüne alınarak yapılan senaryo. }\end{array}$ \\
\hline 6 & $\begin{array}{l}\text { Acil durum ekiplerinin tam olarak görev } \\
\text { yapması, acil çıkış kapılarının optimum } \\
\text { düzeyde kullanıldığı senaryo. }\end{array}$ \\
\hline
\end{tabular}




\subsection{Simülasyon Çalışmasında Acil Çıkış Yolu Belirleme Kistasları}

Simülasyonda, acil çıkış yollarının kifayetliliği ve güvenliliği aşağıdaki kıstaslar istikametinde belirlenmektedir:

- İnsanların boşaltım oranı,

- Kaçış sırasında oluşan sıra dizisinin mahalleri ve teşekkül sebepleri,

- Siralar ve kuyruklardaki insanların kullandığı alanlar,

- Yapılardaki dar geçişler ve boğazların yerleri ve ortaya çıkma sebepleri,

- Sıralar/kuyruklardaki insanların işgal ettiği yerler [8],

- Yangın merdivenlerinin kullanımındaki eksiklik ve hatalar,

- Yüksek sığalı yangın merdiveni gereksinimi ve bu merdivenlere tabiiyet,

- Bekleme ve düzenli olma zamanında güvenlik (Duman optik yoğunluğun yayılımının engellenmesi).

Yığılmaların olduğu yerlerde birbirini engellemeyen, akıcı gidiş geliş yol hareketinin sağlanmasında aşağıdaki mimari tespitlerden faydalanılabilir:

- Kolon, bölme duvar gibi mimari unsurlardan yararlanılarak, yayaların kargaşa oluşturmadan düzenli olarak tahliye çıkış kapılarına ulaşmasını temin etmek,

- Gerçek yönlendirmelerle acil çıkış imkanlarındaki tahliye niceliklerini eşitlemek,

- Kapı aydınlığı, koridorlar, basıncaklar vb. çıkış mahallerinin genişliklerini arttırmak,

- Basıncaklara sahanlı yapılarak kullanıc davranışındaki duruşların tüm hareketi engellemesini önlemek.

\subsection{Simülasyon Parametreleri ve Ofis Binasının Özellikleri}

Kullanılan yazılımda insanlar Steering hareket modu [9] [10] ile tahliye davranışı göstermektedirler. Steering modunda insanlar daha düzenli bir şekilde çıkışa doğru ilerlemekte ve kapılar, geçişler ve çıkışlar önünde yı̆̆ılmadan tahliye olmaktadırlar. Yapılan simülasyon çalıșması ofis ortamında çalışan orta yaşlı yetişkin insan gurubu için tasarlanmıştır. $\mathrm{Bu}$ guruptaki insanların ortalama hızlı yürüyüş hızları 1.32 $\mathrm{m} / \mathrm{sn}$, ortalama omuz genişliği $47.3 \mathrm{~cm}$ ve ortalama adım genişlikleri $45.58 \mathrm{~cm}$ olarak tespit edilip modele eklenmiştir. Simülasyon başladığı anda insanlar hareketlerine başlayıp çıkışa doğru ilerlemektedirler, yani insanlara herhangi bir alarm sonrası bekleme süresi tanımlanmamıştır. Her bir simülasyon için, toplam tahliye sürelerinin sağlıklı bir şekilde karşılaştırılması amacıyla, binada toplam 743 adet insan tanımlanmıştır.

Şekil 1'de tahliye simülasyonunun uygulandığı bir ofis binasının detaylı kat planları, koridor genişlikleri ve kaçış yolları verilmiştir. Binada bodrum, zemin ve zemin üstüne 4 adet kat bulunmaktadır ve ortasında atrium boşluğu olacak şekilde tasarlanmıştır. Bodrum katta yemekhane mekanik sistemler, depolar ve toplantı odalar1 vardır. Zemin katta ofis odaları ve hizmet odaları bulunmaktadır. 1, 2 v 3. katlar genellikle ofis ve toplantı odalarından oluşmakta 4 . kat ise üst yönetimin bulunduğu ofisleri barındırmaktadır. Ayrıca binanın uzunluğu $78 \mathrm{~m}$, genişliği $50 \mathrm{~m}$ ve yüksekliği ise 20 m'dir.

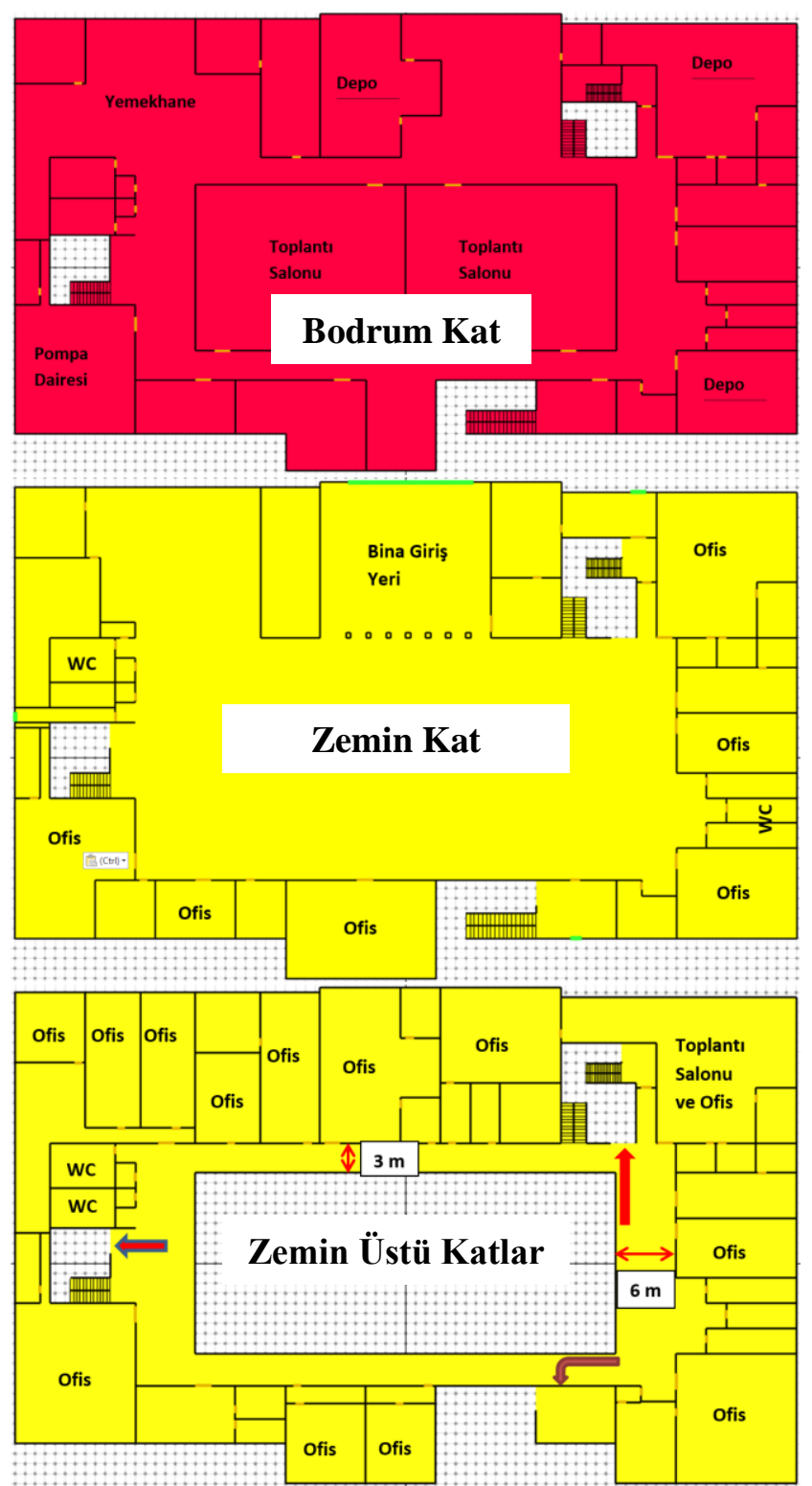

Şekil 1 Tahliye simülasyonu yapılan büro binasının detayları

\subsection{Simülasyon Sonuçları}

Şekil 2'de senaryo 1'e göre bina içerisinde farklı antropometrik özelliklere sahip kullanıcılar için kaotik ortamın simülasyonu yapıldı $\breve{1}$ senaryo görülmektedir. Acil çıkışın sadece arka acil çıkış kapısına yönlendirilerek yapıldığı fakat koridorlardaki ve arka acil çıkış kapısında acil durum tahliye ekiplerinin görevini tam olarak yerine getirmemesi sonucu ortaya çıkan kargaşa gözlemlenmiştir. $\mathrm{Bu}$ senaryoya göre tahliye süresinin uzun olması sonucu 
dumandan etkilenmelerin yoğun olacağı öngörülmektedir. Ayrıca ekiplerin kargaşa ortamında serinkanlı olması gerektiği anlaşılmaktadır ve yüksek kapasiteli yangın basıncağı ihtiyacı gözlemlenmiştir.
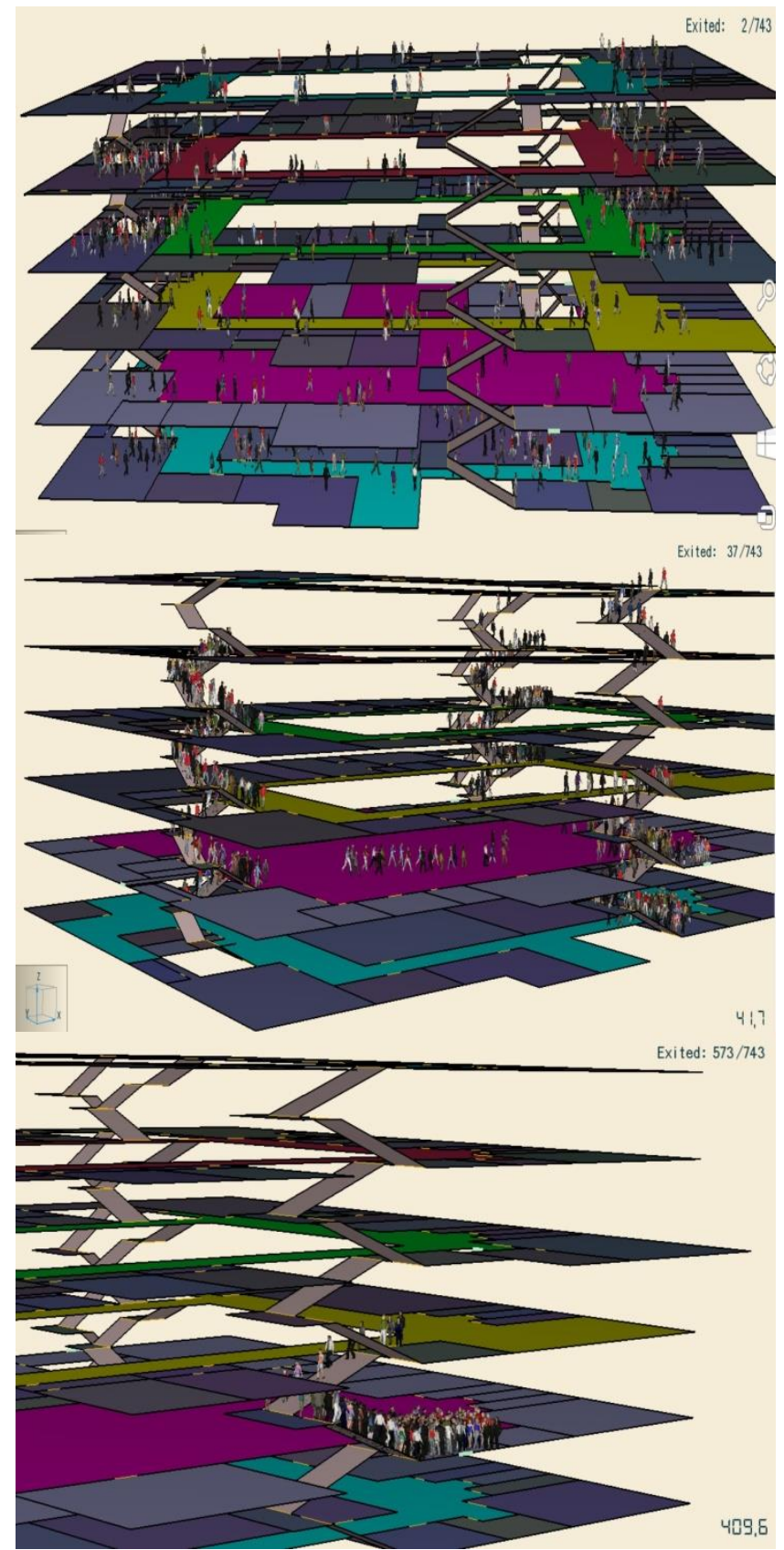

Şekil 2 Arka Acil Çıkıştan Tahliye, Senaryo 1.

Şekil 3 'de senaryo 2'ye göre bina içerisinde çalışanlar haricinde bina daimi kullanıcıları olmayan dışarıdan gelen insanların optik yoğunluğa etkisi sonucunda karmaşa görülmektedir. Tahliye ekiplerinin insanları başarılı bir şekilde yönlendirmesi ve bina içindeki acil çıkış yönlendirme panellerinin de etkisi herkesin Ön Normal Çıkış Kapısına yönlendirilmesi ile oluşan durum irdelenmiştir. Kapının genişliği sayesinde tahliye süresi olumlu yönde etkilenmiştir.
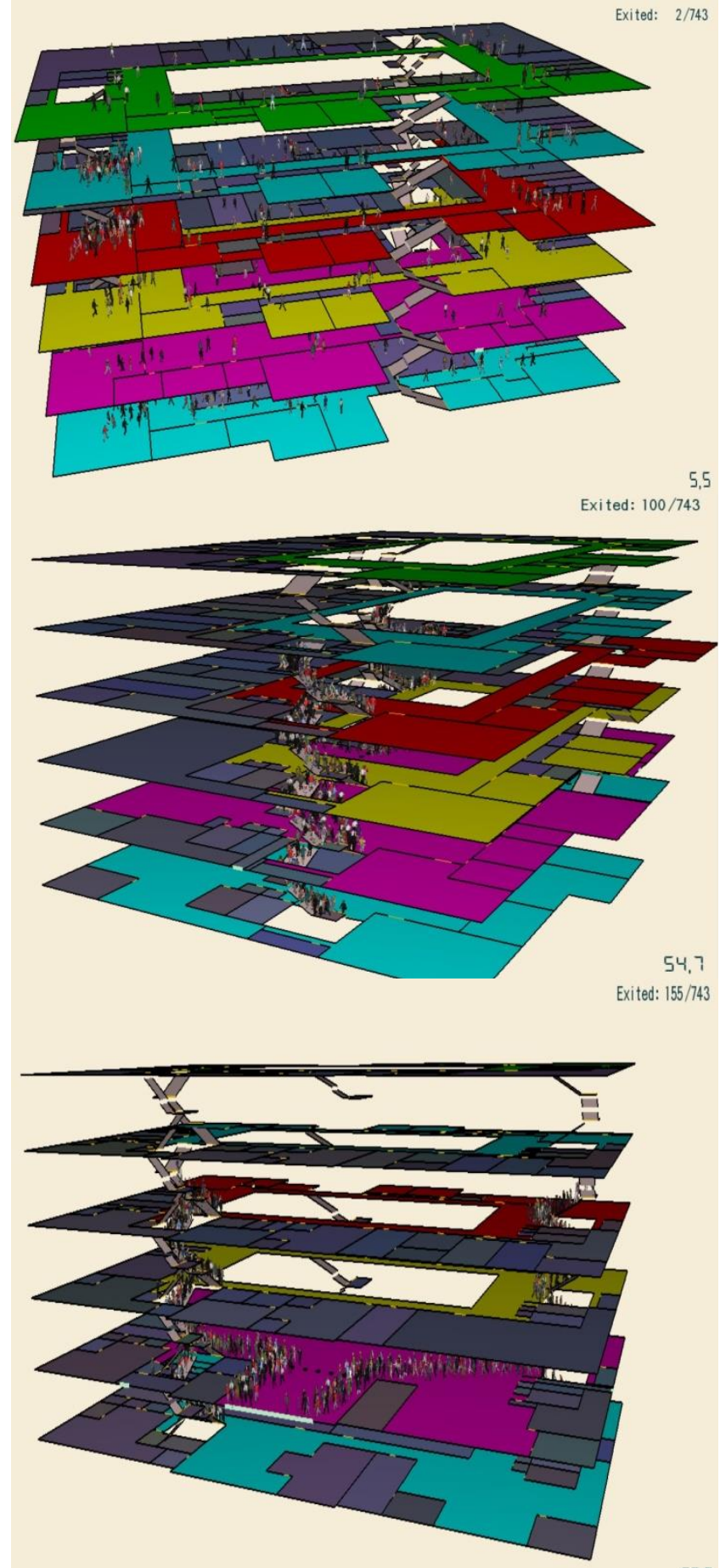

Şekil 3 Ön Normal Çıkış Kapısı Tahliye, Senaryo 2

Şekil 4'de senaryo 3'e göre kaos ortamında kullanıcıların psikolojisi, davranış biçimleri, toksisite, optik yoğunluk ve tahliye ekiplerinin yetersiz kalması gibi durumlar göz önüne alınarak simülasyonda insanları en yakındaki Sağ Ön Acil Çıkış Kapısına doğru yönelmeleri sağlanmıştır. Neticede sıkışıklık, yığılmalar ve dumana maruz kalmalar sonucu kullanıcıların hareketlerinde yavaşlamalar gözlemlenmiş, tahliye süresi 6 dakika 21 saniye ile optimum sürenin üzerinde çıkmıştır. 


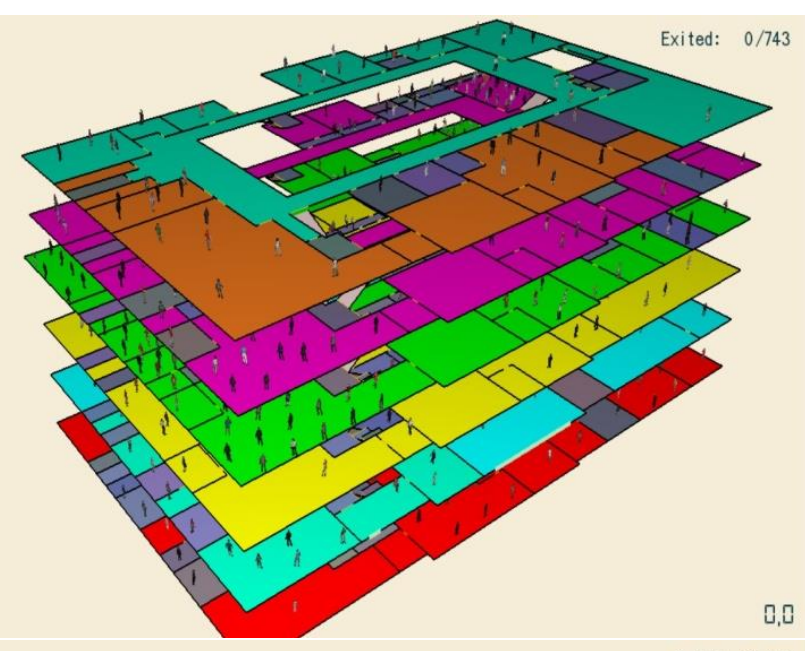

0,0

Exited: $10 / 743$

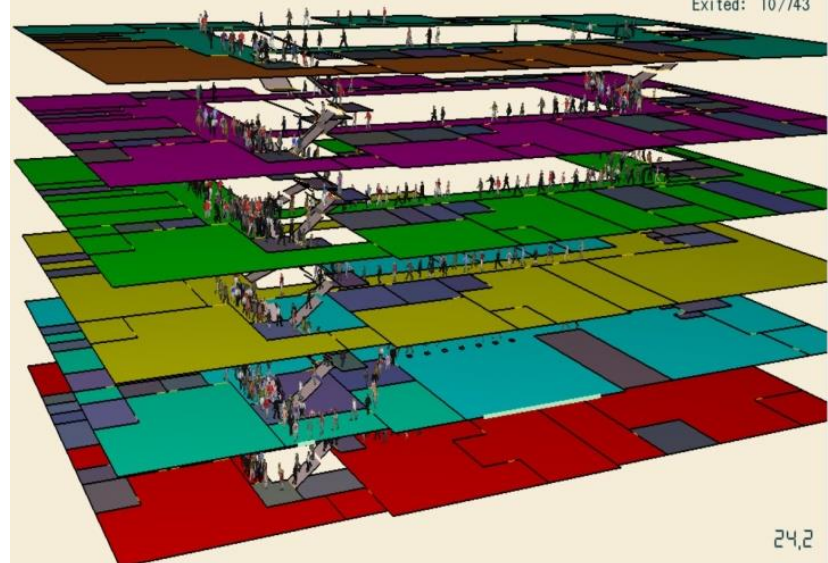

Exited: $400 / 743$

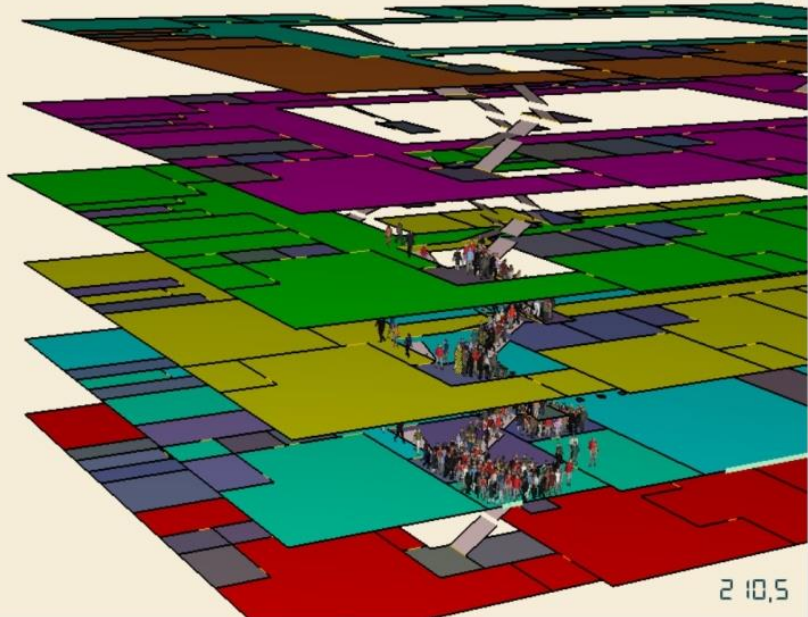

Şekil 4 Sağ Ön Acil Çıkış Kapısı Tahliye, Senaryo 3

Şekil 5'de senaryo 4'e göre Sol Yan Acil Çıkış Kapısı Tahliyesinde kullanıcıların davranış seçimleri, duman içindeki görünebilirlik, kullanıcıların antropometrik özellikleri ve yığılmalar sonucu insanların birbirini sıkıştırdıkları tahliye süresini uzattıkları, bu da ortamdaki optik yoğunluğun insanların sağlığına zarar verdiği gözlemlenmiştir. Ayrıca simülasyon, yangın tehdidi altında bulunana kişilerin tepkilerini ve davranışlarını etkileyen faktörlerin tutarlı bir şekilde anlaşılmasını, güvenilir metodolojilerin uygulanmasına olanak sağlayabilmektedir.
Exited: $0 / 743$
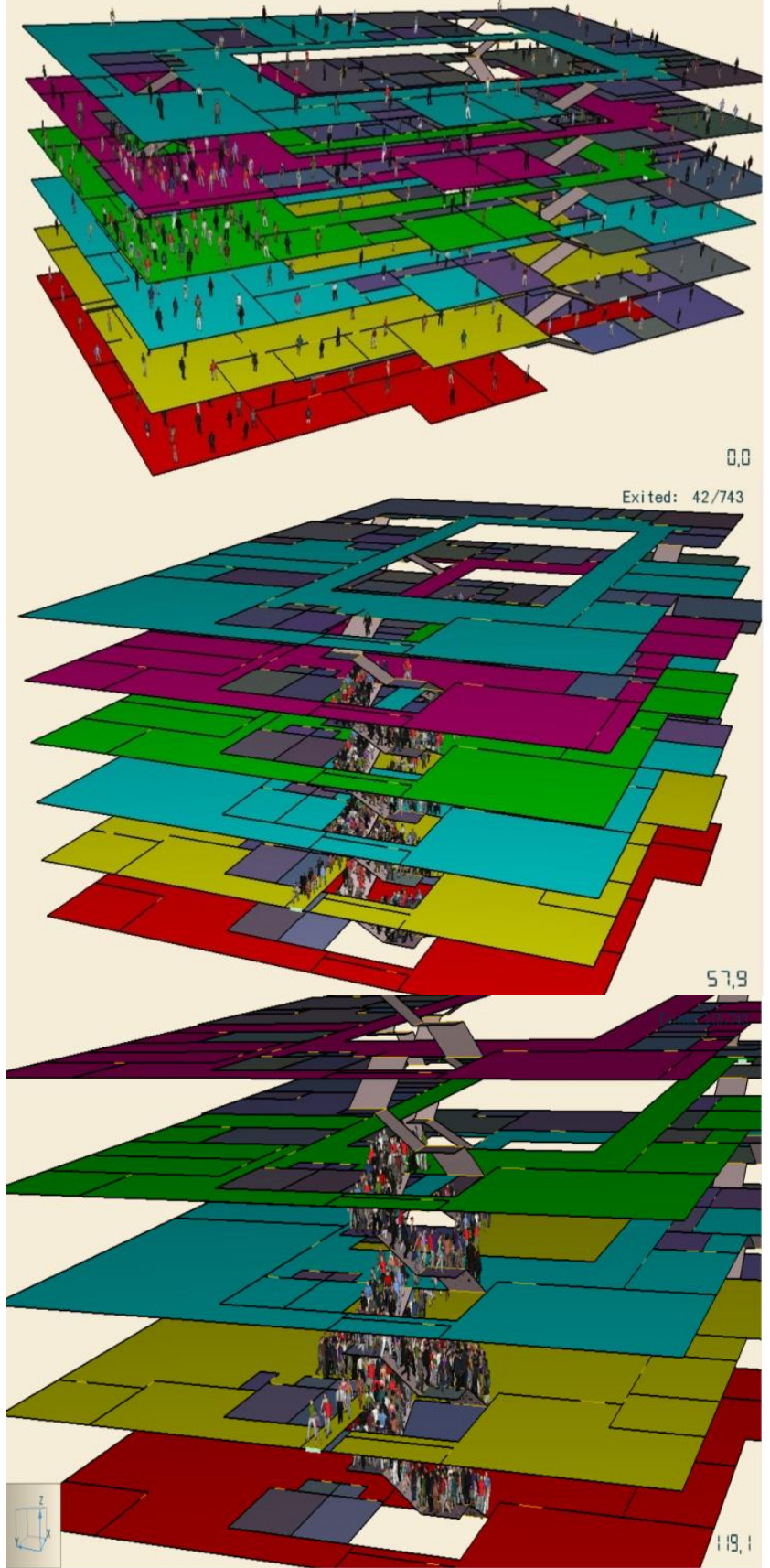

Şekil 5 Sol Yan Acil Çıkış Kapısı Tahliye, Senaryo 4.

Şekil 6'de senaryo 5'e göre günümüzde tahliyeler tasarlanırken daha fazla dikkat edilmeye başlanan dünyasında ENGELSİZ hayatın farkındalığı arttırmak adına ve dezavantajlı insanların hayatlarını kolaylaştırmak için bir simülasyon çalışılması yapılmış ve eksiklikler gözlemlenerek tahliyede engelsiz hayat durumu irdelenmiştir. $\mathrm{Bu}$ simülasyona göre sarı daire içine alınan dezavantaja sahip bir kişi bulunduğu kattaki yangına ve duman sızıntısına dayanıklı bir odaya giderek beklemektedir. Binadaki normal tahliye sona erince eğitimli ve yetkili bir ekip bu odaya giderek bu kişiyi binadan çıkartmaktadır. Bu 
durumda toplam tahliye süresi 10 dakika 50 saniye olarak tespit edilmiştir.
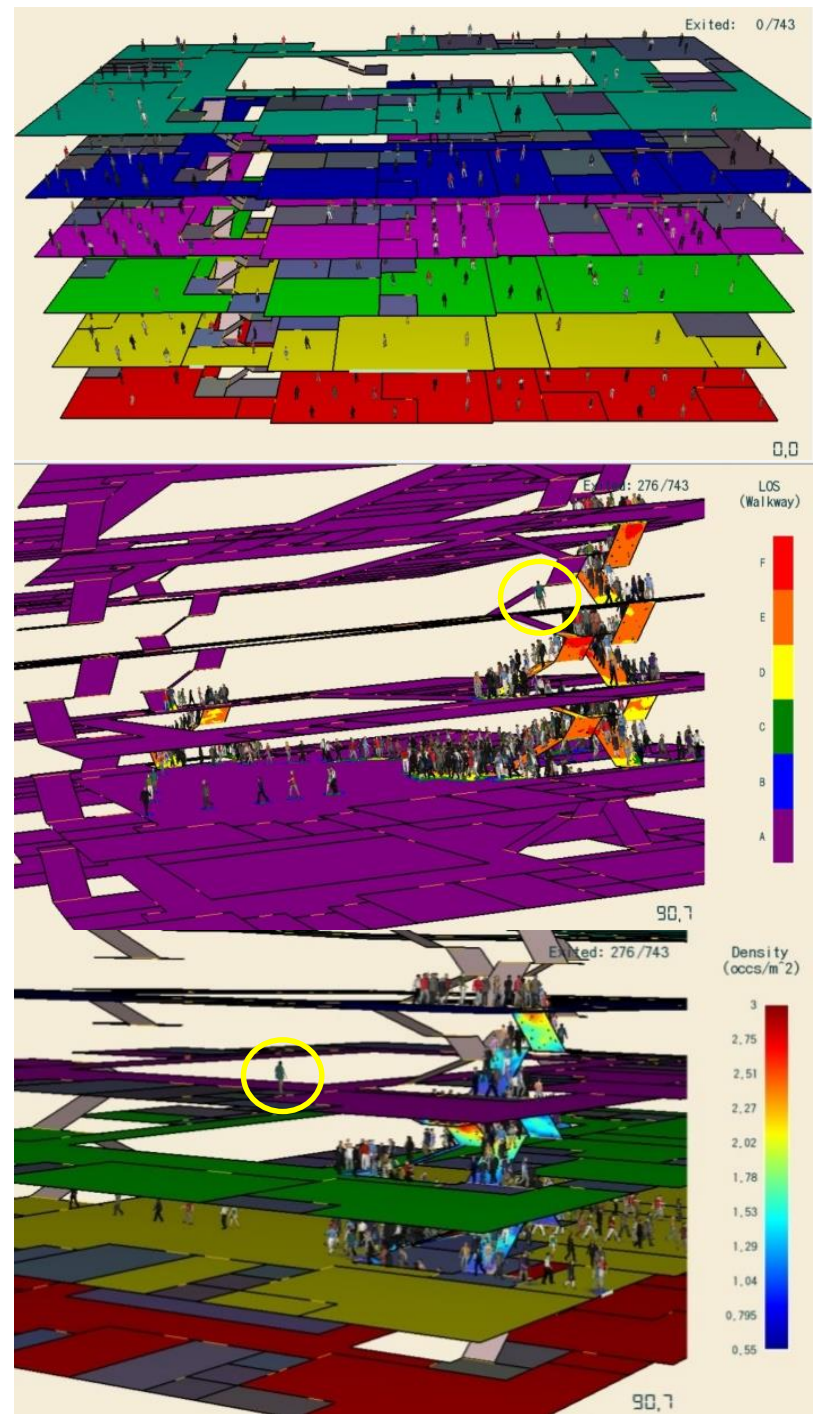

Şekil 6 Engelsiz Hayat Tahliye Simülasyonu, Senaryo 5.

Şekil 7'da senaryo 6'ya göre yapılan örnekte, BYKHY-2015 Madde 126 da belirtilen eğitimli tahliye ekiplerinin 4 farklı acil çıkış kapısına optimum yoğunluğu sağlayacak şekilde yönlendirmesi ile yoğunluk oluşumunu ve kaosu önledikleri görülmektedir. Neticede düzenli tahliye ile 3 dakikanın altında tahliye gerçekleştiği görülmüştür.

Tablo 7'da tüm senaryolar sonucunda ortaya çıkan toplam tahliye süreleri verilmiştir. Buna göre senaryo 4'te sadece tek bir acil çıkış kapısı tahliyesinde toplam süre 11 dakika 35 saniye iken, senaryo 6 de tüm acil çıkış kapılarının efektif kullanımı sonucu toplam süre 2 dakika 53 saniye gibi oldukça düşük bir süreye indirilebilmiştir. Engelsiz hayat senaryosunda süre fazla gözükse se süreyi arttıran nedenin engelli kişiyi bulunduğu güvenli odadan almak için yapılan operasyon olduğu belirtilmelidir.

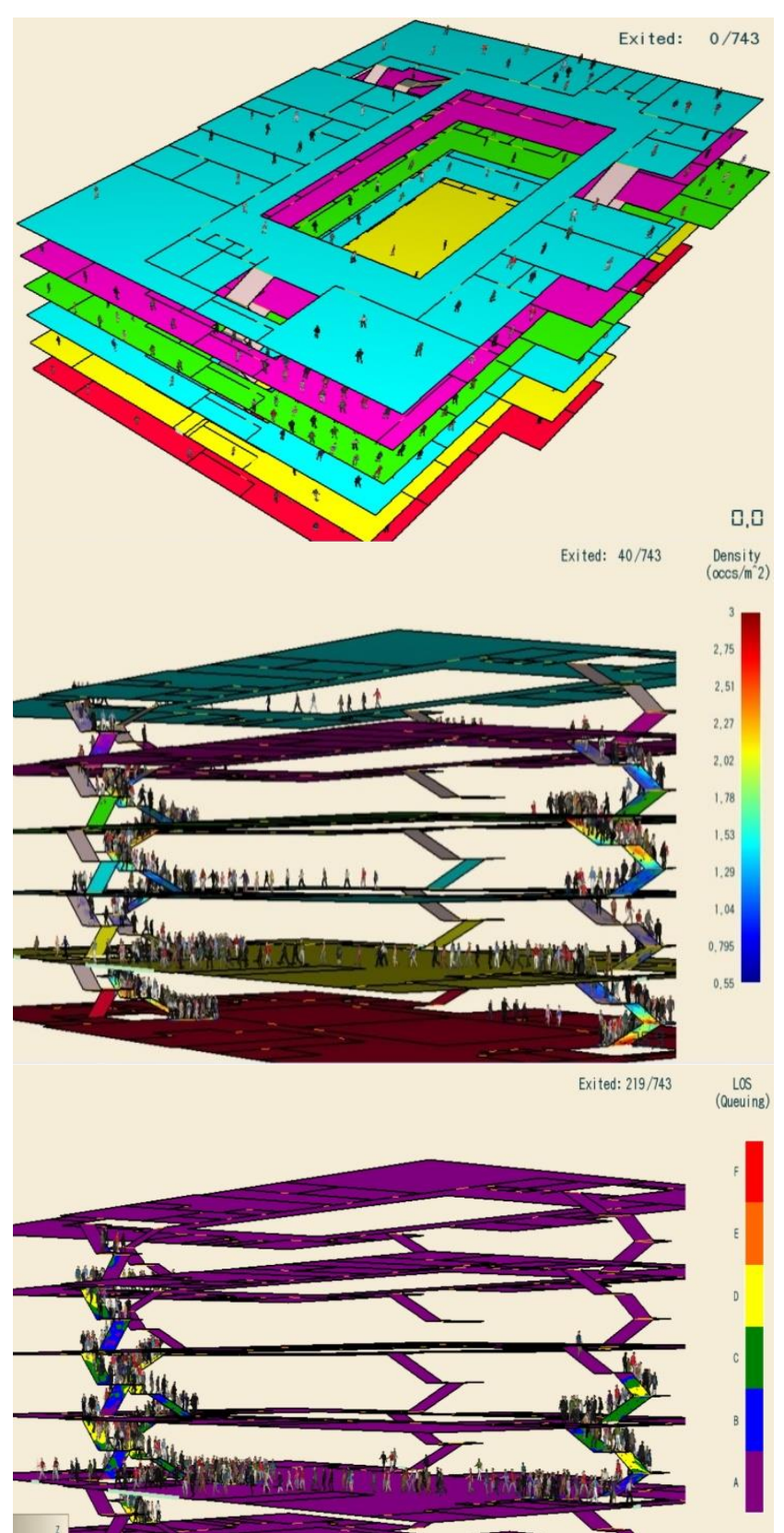

Şekil 7 Tüm Çıkış Kapıları Tahliye, Senaryo 6.

Tablo 7. Senaryoların Tahliye Süreleri

\begin{tabular}{|c|l|l|}
\hline SENARYO & Tahliye Süresi & \multicolumn{1}{|c|}{ ÇIKIŞ YERI KAPISI } \\
\hline $\mathbf{1}$ & 8 DK. $48 \mathrm{SN}$ & $\begin{array}{l}\text { ARKA ACILL ÇIKIŞ } \\
\text { KAPISI }\end{array}$ \\
\hline $\mathbf{2}$ & 3 DK. $13 \mathrm{SN}$ & ÖN GENIŞ ÇIKIŞ KAPISI \\
\hline $\mathbf{3}$ & 6 DK. $21 \mathrm{SN}$ & ÖN ACIL ÇIKIŞ KAPISI \\
\hline $\mathbf{4}$ & $11 \mathrm{DK} .35 \mathrm{SN}$ & SOL YAN ÇIKIŞ KAPISI \\
\hline $\mathbf{5}$ & 10 DK.50 SN & ENGELSİZ HAYAT \\
\hline $\mathbf{6}$ & 2 DK. $53 \mathrm{SN}$ & TÜM ÇIKIŞLAR \\
\hline
\end{tabular}

\section{SONUÇLAR}

$\mathrm{Bu}$ çalışmada bir büro binası mimari tasarımı dikkate alınarak acil durum anında tahliyenin ne şekilde yapılacağını idrak etmek, kaçış yollarında kaçışa mani herhangi bir faktör 
olup olmadığını denetlemek, kaçış yollarında iyileştirme tedbirlerinin gerekip gerekmediğine karar vermek için 6 adet farklı senaryo ile tahliye simülasyonları yapılmıştır. Simülasyonu yapılan senaryolardan elde edilen sonuçlar aşağıda maddeler halinde değerlendirilmiştir.

- Tüm senaryo çalışmaları içerisinde tüm kapılardan tahliyenin gerçekleştiği 6 . senaryoda kullanıcılar binayı en kısa sürede terk etmişlerdir. Fakat her hangi bir yangın anında kullanıcıların tüm kapılara ulaşabilmeleri mümkün olmayabileceği de dikkate alınmalıdır.

- Yangın anında kullanıcıların sadece bir acil çıkıș kapısını kullandığ1 düşünülerek yapılan simülasyonlarda ön acil çıkış kapısından yapılacak tahliyenin diğerlerine göre daha kısa sürede gerçekleşeceği anlaşılmıştır.

- Binada en uzun tahliye arka acil çıkış kapısının kullanıldığı ve tahliyenin yaklaşık olarak 9 dakika sürdüğü senaryodur. Bu süre, yangın anındaki tahliyede kullanıcıların herhangi bir zarar görmeden binayı terk etmeleri için oldukça uzundur.

- Binada dezavantajlı bir bireyin olduğu varsayılarak yapılan senaryoda toplam tahliye süresi yaklaşık 11 dakika sürmüştür. Bu senaryoda dezavantajlı birey güvenli bir odada itfaiye personelini beklemiş ve daha sonra onunla birlikte binayı terk etmiştir. Bu tip binalarda engellilerin güvenli bir şekilde bekleyebileceği odaların hazırlanmasının önemi göz önüne alınmalıdır.

\section{TEŞEKKÜR}

$\mathrm{Bu}$ çalışma Sakarya Üniversitesi Bilimsel Araştırma Projeleri Koordinatörlüğü tarafından 2017-01-06-026 nolu proje kapsamında yapılmıştır.

\section{KAYNAKÇA}

[1] L. Tan, M. Hu, and H. Lin, "Agent-based simulation of building evacuation: Combining human behavior with predictable spatial accessibility in a fire emergency," Inf. Sci. (Ny)., vol. 295, no. C, pp. 53-66, Feb. 2015.

[2] N. Wagner and V. Agrawal, "An agent-based simulation system for concert venue crowd evacuation modeling in the presence of a fire disaster," Expert Syst. Appl., vol. 41, no. 6, pp. 2807-2815, May 2014.

[3] "Binaların Yangından Korunması Hakkında Yönetmelik -(09/07/2015)-29411."

[4] J. Joo et al., "Agent-based simulation of affordancebased human behaviors in emergency evacuation," Simul. Model. Pract. Theory, vol. 32, pp. 99-115, Mar. 2013.

[5] R. AKSOY, G. COSKUN, and H. S. Soyhan, "Developing emergency escape scenarios by using fire simulation softwares," in 6 th International Conference on Renewable Fuels Combustion and Fire, 2017.

[6] X. Zheng, T. Zhong, and M. Liu, "Modeling crowd evacuation of a building based on seven methodological approaches," Build. Environ., vol. 44, no. 3, pp. 437-445, Mar. 2009.

[7] "Pathfinder." Thunderhead Engineering Consultants, Inc., 2018.

[8] D. J. O et al., "SFPE Task Group on Human Behavior in Fire CHAIR."

[9] C. W. Reynolds, "Steering Behaviors For Autonomous Characters."

[10] H. Ben Amor, J. Murray, and O. Obst, "Fast, Neat and Under Control: Inverse Steering Behaviors for Physical Autonomous Agents." 